\title{
Mucosal and systemic antibody responses to the lipopolysaccharide of Escherichia coli 0157 in health and disease*
}

\author{
CAROL G. CURRIE, KIRSTEN MCCALLUM and IAN R. POXTON
} Department of Medical Microbiology, University of Edinburgh Medical School, Teviot Place,
Edinburgh EH8 9AG

Mucosal immunity in the gastrointestinal (GI) tract is a primary defence against GI pathogens. We hypothesise that a mucosal response to lipopolysaccharide (LPS), especially to the common (core) determinants of GI pathogenic Escherichia coli strains, is protective. The aims of this study were to investigate the specificities, levels and development of humoral responses in health and GI disease to the R3 LPS core and O-polysaccharide of $E$. coli 0157 . The purpose was to try to predict whether vaccination or passive immunisation might induce protection. Wherever possible, paired whole gut lavage fluid (WGLF) and serum samples were collected for comparison of the mucosal and systemic responses. Matched saliva samples were also collected from some study groups. The patient groups included those with acute $E$. coli 0157 disease (serum only), patients convalescing after $E$. coli $\mathbf{O 1 5 7}$ infections, and patients undergoing routine investigation for GI conditions but subsequently shown to be immunologically normal. Some samples of WGLF from patients with Crohn's disease (CRO) and ulcerative colitis (UC) were included to allow comparisons with patients with inflammatory conditions known to alter antibody secretion in the GI tract. The healthy groups from whom serum and saliva only were taken included blood donors, healthy volunteers and a group of slaughterhouse workers. This latter group was likely to have been exposed regularly to faecal bacteria from animals and antibody specificities might have been expected to be different from other healthy individuals. Levels and classes of antibodies were determined by ELISA with microtitration plates coated with polymyxin complexes of whole LPS extracted from $E$. coli 0157 and LPS from the $E$. coli R3 rough mutant. Antibodies of IgG and IgM classes were measured in serum and IgA was measured in WGLF and saliva. IgG antibodies to the 0157 LPS and the R3 core oligosaccharide were detected in the serum of healthy blood donors. Patients with acute $E$. coli 0157 disease showed elevated levels of serum IgM to O157 LPS and R3, with IgG levels raised only to $\mathrm{R3}$. In serum from convalescent patients, IgG to 0157 LPS was significantly above the control groups only in the period 6-16 weeks after infection. Total IgA levels were similar in WGLF specimens from all groups, except the patients with $\mathrm{UC}$, whose levels were much higher. Specific IgA levels were higher in the $E$. coli 0157 convalescent group, but there were no significant correlations overall. UC patients had significantly lower levels of IgA to 0157 and CRO patients had higher O157 IgA levels than UC patients and healthy volunteers. In serum, inhibition of ELISA showed that the response to the O157 LPS was due in part to a response to the $\mathrm{R} 3$ oligosaccharide component. This response was much more pronounced in the healthy and non-0157 groups than in convalescent patients. There was no correlation between specific IgA antibody levels in saliva and matched specimens of WGLF, and levels in sequential saliva specimens fluctuated widely. The significant IgG and IgA responses to the $\mathrm{R3}$ core suggest that there is immunological memory to this oligosaccharide LPS component which may have a role in protection against $E$. coli LPS both systemically and locally in the GI tract. Boosting of this mucosal response to the LPS core, either naturally through exposure or by active or passive immunisation, may confer protection. Finally, antibody responses to $E$. coli 0157 must be interpreted with caution, as the response detected is a sum of responses to the $\mathrm{O}$-specific polysaccharide and the $\mathrm{R} 3$ core.

Received 16 May 2000; revised version received 1 Sept. 2000; accepted 17 Sept. 2000.

Corresponding author: Professsor I.R. Poxton (e-mail: i.r.poxton@ed.ac.uk).

* Dedicated to the memory of Professor Anne Ferguson. 


\section{Introduction}

Strains of Escherichia coli $\mathrm{O} 157$ and other enterohaemorrhagic E. coli (EHEC) are now well recognised as causes of significant morbidity and mortality in the young and the elderly [1]. Infections caused by these strains - haemorrhagic colitis, haemolytic uraemic syndrome (HUS) and thrombocytopenia purpura appear to be more common in Scotland than the rest of the UK [2,3]. Because of increased incidence of disease at the extremes of age there is a suggestion that immunity may influence susceptibility to disease. It is also likely that local mucosal defences in the gastrointestinal (GI) tract may be more important than systemic immunity [4].

EHEC strains possess an array of virulence factors that includes Shiga (Vero) cytotoxins, products of the locus of enterocyte effacement (LEE) pathogenicity island, which are involved in the attaching and effacing lesion, and lipopolysaccharide (LPS) [1]. LPS may be responsible for the direct upregulation of Gb3 (the receptor for the Shiga toxin on target tissues) or the action may be indirect through induction of tumour necrosis factor (TNF)- $\alpha$ and other pro-inflammatory cytokines $[5,6]$. The combined action of LPS and Shiga toxin has been reported to be synergic [7].

The LPS molecule consists of three main domains the O-specific antigenic polysaccharide, the core oligosaccharide, which is antigenic, and lipid A. The latter domain is reasonably well conserved between different genera and is responsible for much of the biological activity of the molecule. In $E$. coli there are at least 160 different serotypes, each with a different O-polysaccharide, and even within a serotype there is heterogeneity of chain length of the polysaccharide. The core oligosaccharide that links the lipid A to the O-polysaccharide can be of five types, denoted R1-R4 and K12. In several surveys, R1 has been shown to be the most common core type in the LPS of E. coli strains, with the R3 type being uncommon [8,9]. Although not based upon an exhaustive study, our experience indicates that the R3 core is more common in the LPS of diarrhoeagenic strains of $E$. coli, including many enterotoxigenic and enteropathogenic E. coli (ETEC and EPEC) strains and some shigellae, than in normal faecal isolates of E. coli. In a study of normal faeces, only two of 21 faecal isolates examined had the R3 core [8]. However, a further study showed that the core type of all 28 EHEC strains of $\mathrm{O} 157$ and non-O157 serotypes were of the R3 chemotype [10]. This has been largely supported by recent work by Amor et al. [11], who showed by PCR that the great majority of verocytotoxigenic $E$. coli (VTEC) strains possessed the R3 core. The complete core oligosaccharide-lipid A (R-form LPS) is naturally expressed on wild-type smooth bacteria and is accessible to antibody; it is visualised as the bottom 'rung' of the ladder pattern in SDS-PAGE [12].

Mucosal immunity in the GI tract is a primary defence against GI pathogens. We have hypothesised that immunity to LPS, especially in the GI mucosal immune system, may protect against LPS-mediated responses [13] and against diarrhoeal infections in the GI tract, especially in the developing world [14]. As discussed later, most studies of immunity to EHEC have concentrated on measuring systemic immunity in serum. The present study examined mucosally produced antibodies obtained by the well-validated, noninvasive technique of whole gut lavage $[15,16]$.

The aims of this study were to investigate, in both the mucosal and systemic compartments of the immune system, the specificities, levels and development of humoral responses in health and GI disease to the main antigenic domains - the R3 LPS core and Opolysaccharide - of E. coli O157. The purpose of the study was to predict whether vaccination or passive immunisation might induce protection.

\section{Materials and methods}

\section{Patients and specimens}

Paired sera and WGLF were obtained from five groups of subjects: healthy volunteers (HV: $\mathrm{n}=20,17$ female and 3 male; age range 21-52 years, mean 33 years); patients convalescing normally from E. coli $\mathrm{O} 157$ infection, 8-113 weeks after infection (CON: $n=9,7$ female and 2 male; age range $23-67$ years, mean 50 years); patients with ulcerative colitis (UC: $n=24,13$ female and 11 male; age range 14-88 years, mean 44 years) and Crohn's disease (CRO: $n=11,7$ female and 4 male; age range $24-69$, mean 45 years) and a group of patients in the Gastrointestinal Unit (GI: $n=53,34$ female and 19 male; age range 18-77 years, mean 46 years) from whom samples were taken at the time of routine clinical investigations, but who were subsequently shown to be immunologically normal.

Sera only were collected from five groups: random healthy adult blood donors (BTS: $n=647$; anonymous gender and age not known); slaughterhouse workers (SH: $\mathrm{n}=10,1$ female and 9 male; age range $24-56$ years, mean 31 years); healthy volunteers (HV: $n=25$, 12 female and 13 male; age range 21-54 years, mean 31 years); patients on presentation to hospital with symptoms later confirmed as being caused by $E$. coli O157 (Acute: $\mathrm{n}=5$, age and gender unknown); and convalescent patients $(\mathrm{CON}: \mathrm{n}=15 ; 9$ female and 6 male; age range 26-66 years, mean 49 years).

Saliva samples were collected from a small number of subjects; there were 10 matched pairs of saliva and WGLF ( $3 \mathrm{CON}$ and $7 \mathrm{HV}$ ), and a further 36 saliva samples without WGLF (6 CON, $22 \mathrm{HV}, 8 \mathrm{SH}$ ). Saliva 
was taken directly from the parotid duct by means of a Carlsson-Crittenden cup, with gentle suction, after induction of saliva by a few drops of lemon juice on the tongue.

\section{Whole gut lavage fluid (WGLF)}

WGLF is a clear liquid obtained per rectum after the subject has drunk 4-5 L of an isotonic polyethylene glycol-based fluid (Kleen-prep, Norgine, Oxford) as described previously [13]. Approximately $50 \mathrm{ml}$ of WGLF were collected, filtered and treated with protease inhibitors and stored at $-70^{\circ} \mathrm{C}$ in divided volumes. Full ethical approval was obtained for the study, and all patients and volunteers gave their informed consent.

\section{Batch cultures of bacterial strains}

A clinical isolate of E. coli O157:H7 (MPRL 4252) and an E. coli R3 rough mutant strain (MPRL 2318) were each inoculated into $2 \mathrm{~L}$ of filter-sterilised nutrient broth (Gibco). They were incubated in an orbital incubator $(120 \mathrm{rpm})$ at $37^{\circ} \mathrm{C}$ overnight; bacteria were harvested by centrifugation at $10000 \mathrm{~g}$, washed in PBS and freeze-dried.

\section{Preparation of LPS}

The smooth LPS from E. coli $\mathrm{O} 157$ was extracted by the aqueous phenol method of Westphal and Luderitz from lyophilised bacteria as described by Hancock and Poxton [17]. The rough LPS from the R3 mutant strain was extracted by the phenol/chloroform/petroleum spirit (PCP) method of Galanos and colleagues described by Hancock and Poxton [17].

\section{Enzyme-linked immunosorbent assays (ELISA)}

Total IgA in WGLF. Total secreted IgA in WGLF was assayed by ELISA with a modification of the method described previously [15] in 96-well microtitration plates (Immulon ${ }^{\circledR} 1$, Dynex Technologies). All reactants (with the exception of the blocking solution) were added in volumes of $100 \mu \mathrm{l} /$ well and all washes were done four times with PBS ( $\mathrm{pH} 7.3$ ) containing Tween $20 \quad 0.05 \%$ and sodium azide $0.05 \%$. IgA standard, WGLF and conjugate were diluted in blocking solution ( $\mathrm{NaCl} 0.9 \%$ containing adult bovine serum $1 \%$ and Tween $200.05 \%$ ). The plates were coated with rabbit anti-human IgA (Dako A-0262) diluted 1 in 600 in $0.05 \mathrm{M}$ sodium carbonate buffer ( $\mathrm{pH}$ 9.6) containing sodium azide $0.02 \%$, incubated overnight at $4{ }^{\circ} \mathrm{C}$ and washed. The plates were then coated with blocking solution, $200 \mu \mathrm{l} /$ well, incubated for $1 \mathrm{~h}$ at room temperature and then washed. Serial two-fold dilutions $(1000-31.25 \mathrm{ng} / \mathrm{ml})$ of a human colostrum IgA standard (Sigma I-0633) and serial dilutions of WGLF commencing at 1 in 200 were added to the coated wells. Plates were incubated overnight at $4^{\circ} \mathrm{C}$ then washed. Goat anti-human IgA ( $\alpha$-chain specific) alka- line phosphatase conjugate (Sigma A-3063) diluted 1 in 10000 was added to the plates, incubated at room temperature for $3 \mathrm{~h}$ and washed. After developing with p-nitrophenyl phosphate (Sigma 104), the optical density at $405 \mathrm{~nm}\left(\mathrm{OD}_{405}\right)$ was read in an Anthos 2001 plate reader. A standard curve was produced and the IgA content of the WGLF samples was determined from the dilution that gave an $\mathrm{OD}_{405}$ value within the range of the curve.

O157 LPS and R3 core specific IgA in WGLF. LPS was first complexed with polymyxin $B$ sulphate by a modification of the method developed by Scott and Barclay [18]. This method is well validated and has been used extensively in this laboratory for $>10$ years. Briefly, lyophilised LPS was resuspended in $2 \mathrm{ml}$ of pyrogen-free water to a concentration of $1 \mathrm{mg} / \mathrm{ml}$. This solution was mixed with polymyxin B sulphate $(2 \mathrm{ml}$ of a $1 \mathrm{mg} / \mathrm{ml}$ solution) in a Reactivial (Pierce) and sonicated in short bursts for $30 \mathrm{~s}$ in an ultrasonicator (MSE Soniprep) set at $10 \mu \mathrm{m}$. The solution was stirred at room temperature for $90 \mathrm{~min}$, then dialysed in 2000 MWCO Spectra/Por ${ }^{\circledR}$ dialysis membrane bags overnight against pyrogen-free water at $4^{\circ} \mathrm{C}$ to remove excess polymyxin. After removal from the dialysis bags, the complex was re-sonicated as described previously. It was then diluted in coating buffer (as above) to give a final LPS concentration of $20 \mu \mathrm{g} / \mathrm{ml}$, loaded $(100 \mu \mathrm{l} /$ well) on microtitration plates (Immulon ${ }^{\circledR}$ 2, Dynex Technologies) and incubated at $4^{\circ} \mathrm{C}$ overnight. The plates were then washed four times as above, post-coated (200 $\mu \mathrm{l} /$ well) with PBS (pH 7.4) containing Teleostean fish gelatin (Sigma) 2\% and sodium azide $0.05 \%$ (blocking solution) and incubated at $4^{\circ} \mathrm{C}$ overnight followed by washing. The WGLF samples were diluted 1 in 2 in PBS ( $\mathrm{pH} \mathrm{7.4)} \mathrm{containing}$ Tween $200.05 \%$ and sodium azide $0.05 \%$ and loaded (100 $\mu \mathrm{l} /$ well) on microtitration plates and incubated at room temperature overnight. After further washing, $100 \mu 1$ of anti-human IgA ( $\alpha$-chain specific) alkaline phosphatase-conjugated antibody (Sigma A-3063) diluted 1 in 1000 were added and incubated at $37^{\circ} \mathrm{C}$ for $90 \mathrm{~min}$. After the final wash alkaline phosphatase substrate (as above) was added (100 $\mu \mathrm{l} /$ well) and the $\mathrm{OD}_{405}$ was recorded after incubation for $40 \mathrm{~min}$ (for O157-coated plate) or $80 \mathrm{~min}$ (for R3-coated plate) at room temperature. The inter-assay controls were WGLF samples that gave an $\mathrm{OD}_{405}$ value of $c .1 .0$ at the end of the substrate incubation period. The specific antibody levels were standardised by reference to the total IgA and expressed as OD units $/ 100 \mu \mathrm{g}$ total IgA.

Specific IgG and IgM antibodies in serum. These were assayed as for specific IgA except that serum was diluted 1 in 20 and the anti-human $\operatorname{IgG}(\gamma$-chain specific) alkaline phosphatase-conjugated antibody (Sigma A-3187) and the anti-human $\operatorname{IgM~(~} \mu$-chain specific) alkaline phosphatase-conjugated antibody (Sigma A-3187) were diluted 1 in 2000. The substrate incubation times were $30 \mathrm{~min}$ (for O157-coated plates) 
and $90 \mathrm{~min}$ (for R3-coated plates). The inter-assay controls were serum samples that gave an $\mathrm{OD}_{405}$ of c. 1.0 at the end of the substrate incubation period.

Inhibition ELISA. An inhibition ELISA was performed to determine whether the specificities of the antibodies in serum were to the O157 O-polysaccharide or to the R3 core. The inhibition step, with E. coli R3 LPS, was done before the antibody was added to the O157 LPScoated plates. Samples of serum were diluted 1 in 10 in PBS containing Tween $200.05 \%$ and sodium azide $0.05 \%$ and mixed with an equal volume of $\mathrm{R} 3$ core inhibitor to give a final dilution of 1 in 20 and inhibitor concentration of $1 \mathrm{mg} / \mathrm{ml}$. The concentration of inhibitor had been previously determined to give maximum inhibition (data not shown). Samples were then incubated for $30 \mathrm{~min}$ at $37^{\circ} \mathrm{C}$ before adding to the O157 LPS-coated plates.

Statistical analyses were by unpaired Student's $t$ test with Sigmaplot $^{\circledR}$ (Jandel scientific Software) or Microsoft Excel.

\section{Results}

Specific antibody to 0157 LPS and R3 core in serum

Initial assays were performed to determine the relative levels of $\operatorname{IgG}$ antibodies to the two antigenic domains of E. coli O157 LPS in sera from healthy individuals (anonymous blood donors). Microtitration plates were coated with whole LPS-polymyxin complexes from $E$. coli $\mathrm{O} 157$ or $\mathrm{R} 3$ strains. IgG antibodies to both $\mathrm{O} 157$ and R3 core antigens were detected in all individuals. The pattern of distribution of these specific antibodies in the general population was similar for both antigens. However, values varied greatly, with both mean and median towards the lower end of the ranges. Several individuals had very high levels of antibodies to both antigens. The results are summarised in Fig. 1 and ranged from $2 \%$ to $>800 \%$ of the mean $(0.44$ OD units) for R3 core and from $2 \%$ to $>400 \%$ of the mean (0.62 OD units) for O157 LPS.

Specific serum IgG antibody levels were determined for the groups of patients and healthy volunteers. The results are summarised in Fig. 2. These graphs permit comparisons between serum IgG antibody levels to O157 LPS and the R3 core in healthy volunteers (including $\mathrm{SH}$ workers), the GI immunologically normal' group and the CON group. Only in the convalescent patients during the period 6-16 weeks after infection are there significantly higher levels (mean 0.83 OD units) of IgG to O157 LPS, compared with the other groups: HV, mean 0.46 OD units $(\mathrm{p}=$ $0.08)$; $\mathrm{SH}$ workers, mean 0.22 OD units $(\mathrm{p}=0.005)$ and GI patients, mean 0.44 OD units $(p=0.008)$. The CON group 21-113 weeks after infection had similar levels of serum IgG to O157 LPS (mean 0.52 OD units) and R3 core (mean 0.46 OD units) to those of the HV group (mean 0.46 and 0.43 OD units, respectively). HV (mean $0.43 \mathrm{OD}$ units) and $\mathrm{SH}$ (mean 0.35 OD units) groups had lower levels of $\operatorname{IgG}$ to R3 than GI patients (mean 0.56 OD units; $p=0.07$ and $\mathrm{p}=0.09$, respectively).

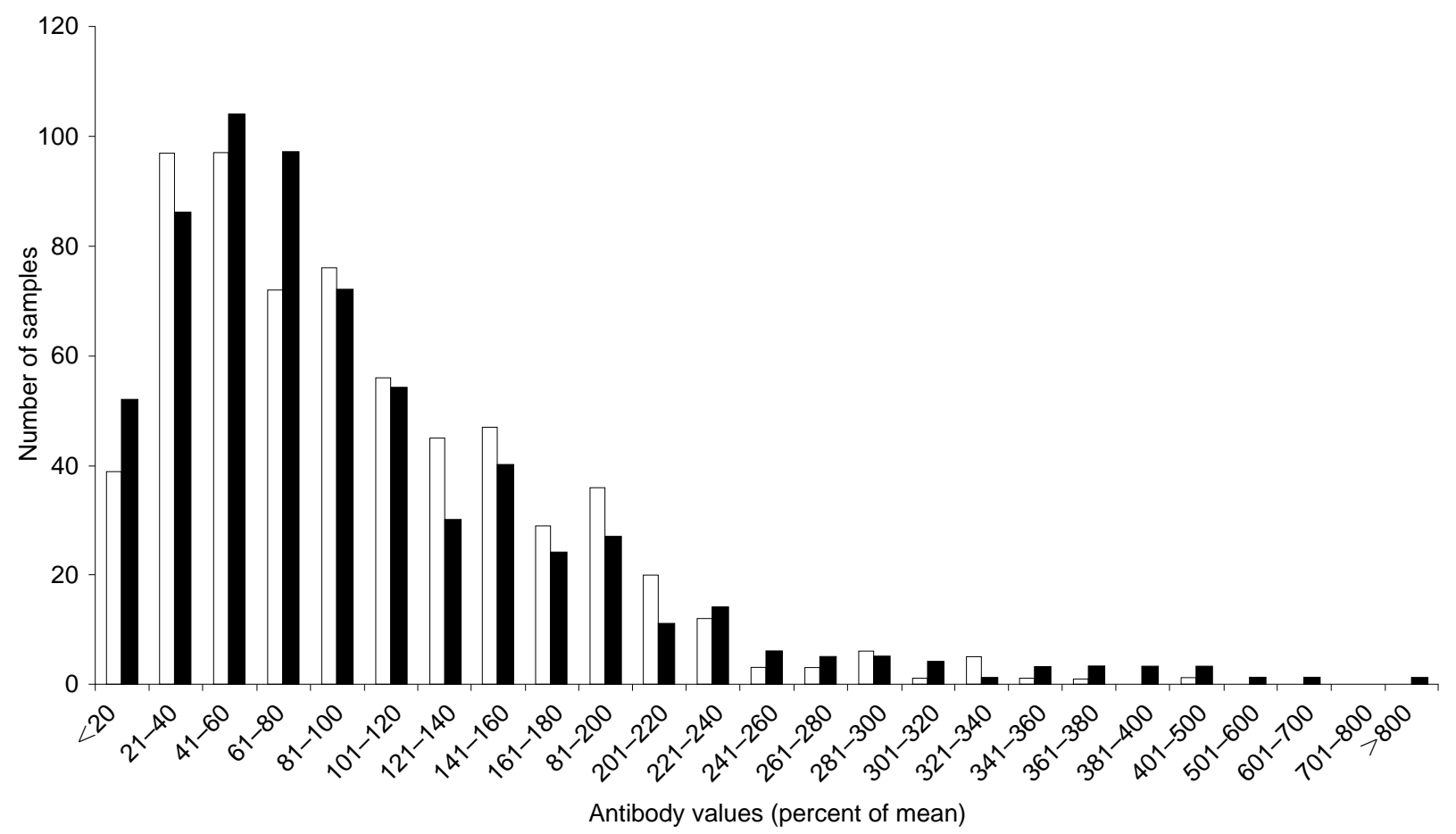

Fig. 1. IgG antibody levels to E. coli O157 LPS ( $\square$, mean value 0.62) and R3 core LPS ( $\square$, mean value 0.44 ) in the sera of healthy controls (anonymous blood donors, $\mathrm{n}=647$ ) as determined by ELISA. The percent mean values are based on a preliminary subset of samples. 
a

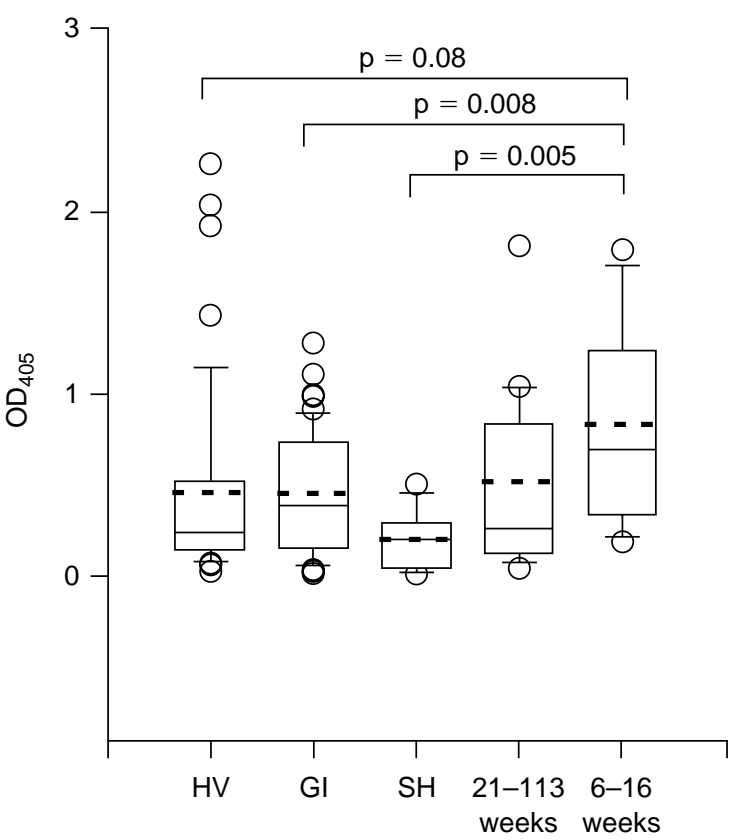

b

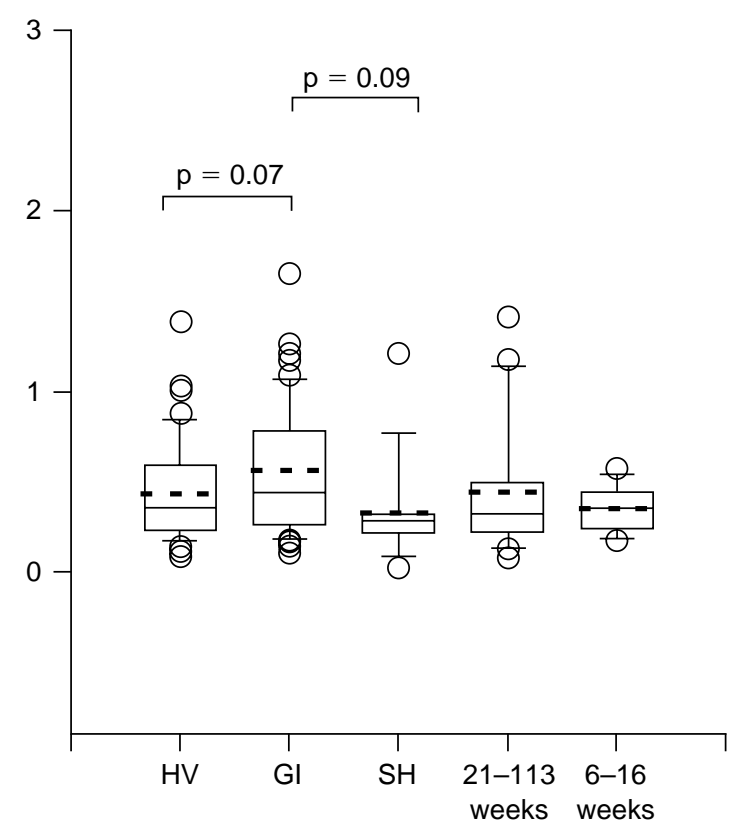

Fig. 2. Comparison of serum IgG antibody responses to (a) O157 LPS and (b) R3 core LPS as OD 405 determined by ELISA. Box plots show differences between different patient and control groups: healthy volunteers (HV); GI 'immunologically normal' patients (GI); slaughterhouse workers (SH); convalescent (CON) patients 21-113 weeks after infection (21-113 weeks) and CON patients 6-16 weeks after infection (6-16 weeks). Box plots: the solid line within the box is the median and the dotted line is the mean; the top and bottom solid lines of the box represent the 75th and 25 th percentiles, respectively, and the small lines outside the top and bottom of the box represent the 90th and the 10th percentiles, respectively.

In a similar analysis, IgM levels against $\mathrm{O} 157$ and R3 antigens were measured. The results for the $\mathrm{HV}$ and patient groups are summarised in Fig. 3. In contrast to IgG levels, the HV group had higher levels of IgM to O157 LPS (mean 0.80 OD units) and R3 core (mean 0.62 OD units) than GI patients (mean 0.52 and 0.41 OD units, respectively; $\mathrm{p}<0.005$ and $\mathrm{p}<0.005)$. The
CON groups did not have levels of IgM significantly different from the HV or any of the other groups. The $\mathrm{SH}$ group had higher levels of IgM to R3 core (mean 0.83 OD units) than the HV (mean 0.62 units; $p=0.007$ ) and GI (mean 0.41 OD units; $p<0.005$ ) groups.

In Fig. 4, IgM and $\operatorname{IgG}$ antibody levels in sera from

a

b
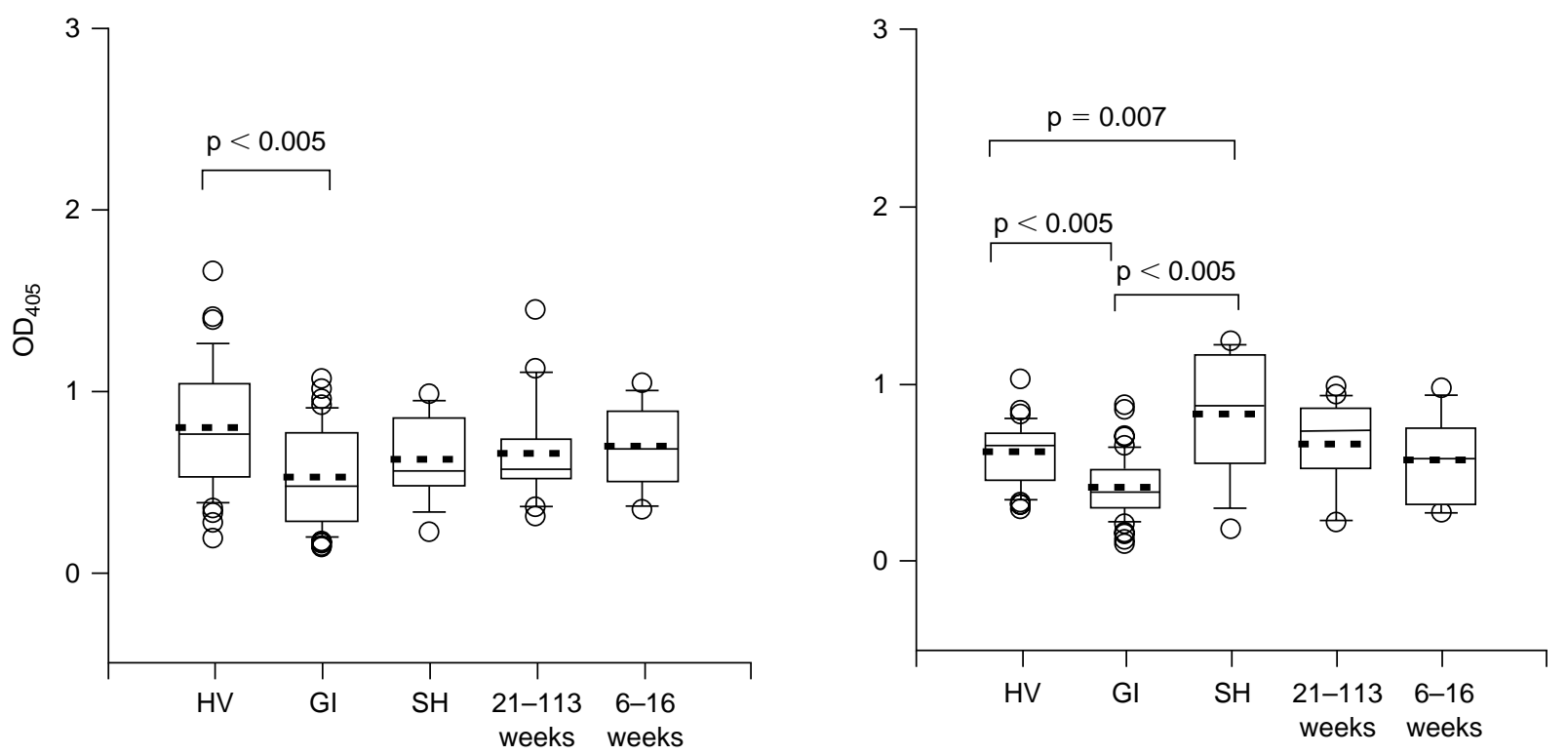

Fig. 3. Comparison of serum IgM antibody responses to (a) O157 LPS and (b) R3 core LPS as OD 405 determined by ELISA. See legend to Fig. 2 for details of box plots and subject groups. 


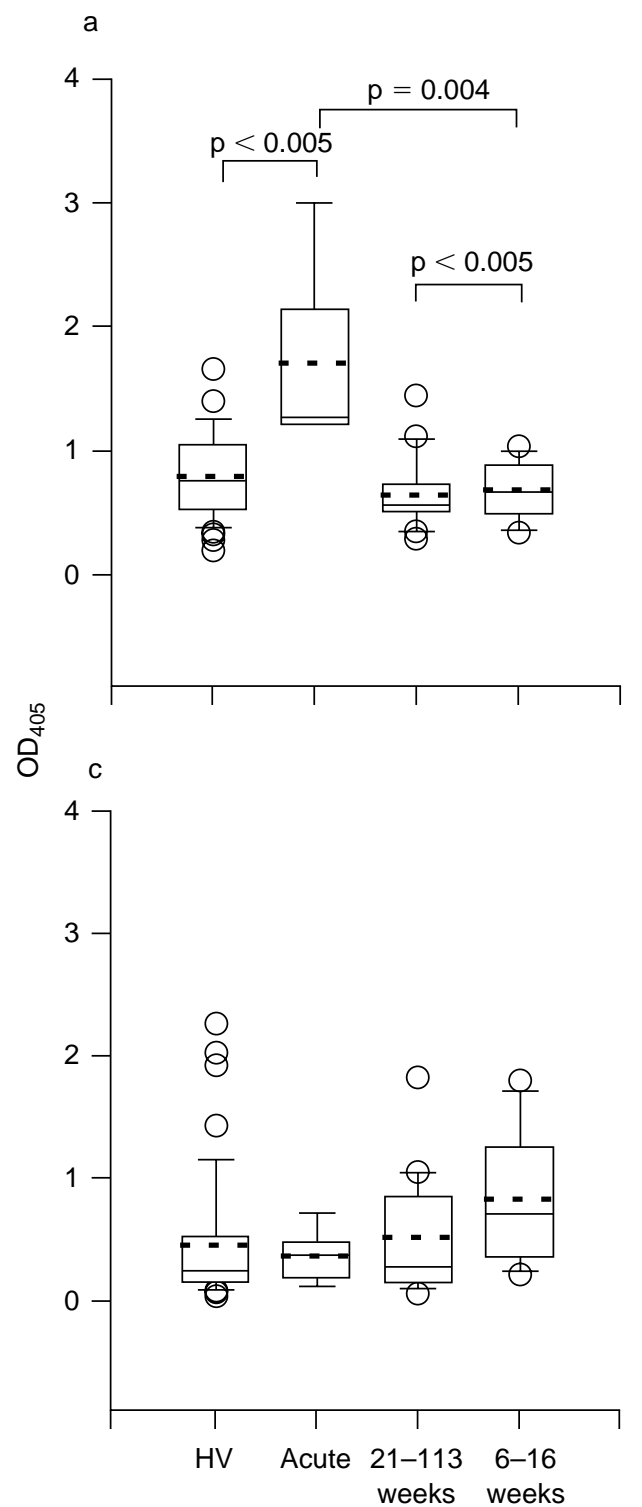

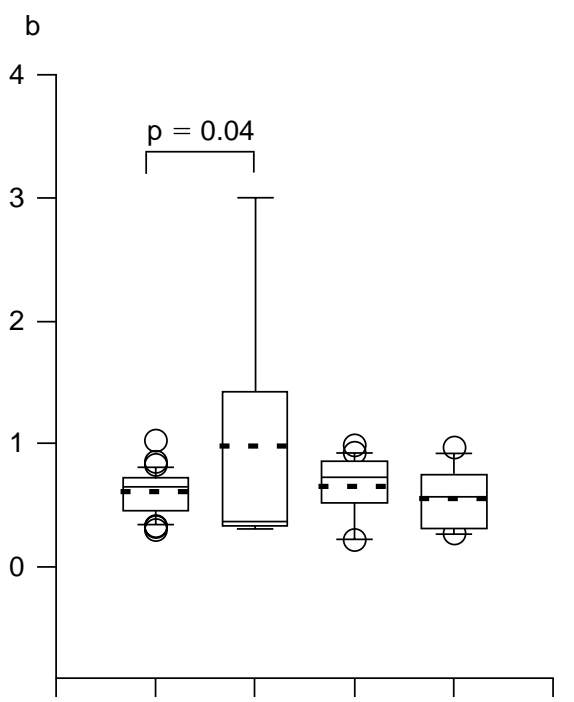

d

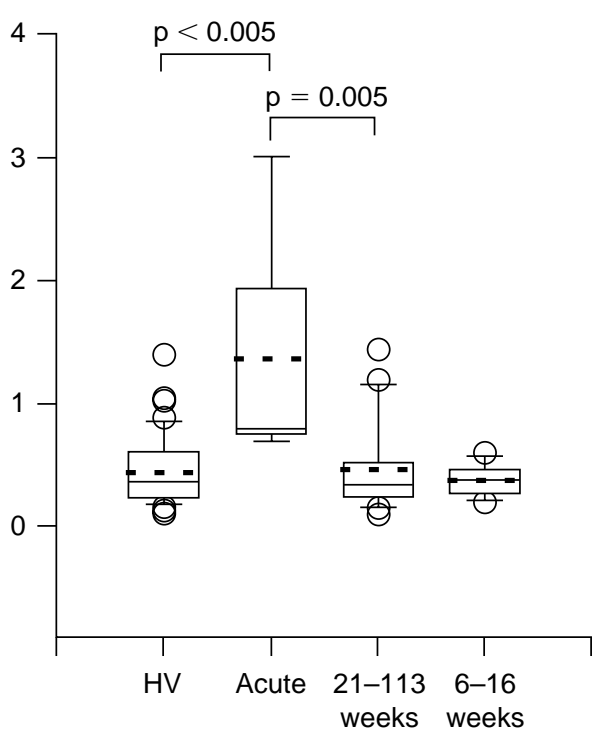

Fig. 4. Serum IgM and IgG antibody responses to O157 LPS and R3 core LPS as $\mathrm{OD}_{405}$ determined by ELISA. a, IgM to O157 LPS; b, IgM to R3 LPS; c, IgG to O157 LPS; d, IgG to R3 LPS. Healthy volunteers (HV); patients with acute disease (Acute); convalescent (CON) patients 21-113 weeks after infection (21-113 weeks) and CON patients 6-16 weeks after infection (6-16 weeks). See legend to Fig. 2 for details of box plots

five patients with acute disease were compared with the CON and HV groups. IgM levels to O157 LPS were markedly higher (mean 1.71 OD units, $\mathrm{p}<0.005$ ) in the acute group than in the other groups (Fig. 4a). This difference was less marked for antibodies to the R3 core LPS (Fig. 4b). IgG levels to the O157 LPS were not significantly different from each other, but the mean level was highest in the most recent convalescent group (Fig. 4c). The levels of IgG antibodies to the R3 core LPS (Fig. 4d) were significantly higher in the acute group (mean 1.36 OD units) than in the HV group (mean 0.43 OD units; $p<0.005$ ) and both CON groups (means 0.46 and 0.37 OD units: $\mathrm{p}=0.005$ and 0.01 , respectively).

\section{Total IgA in WGLF}

WGLF represents a diluted perfusate of all the molecules that are secreted into the whole length of the GI tract during the passage of the lavage fluid. The flow rate is kept as constant as possible by a skilled research nurse monitoring input and output, and values of individual molecules reflect the rate at which they are produced. The values for total IgA levels in WGLF are summarised in Table 1 . There were no statistically significant differences in mean levels between the HV group, the 'immunologically normal' GI patients and the patients convalescing after E. coli $\mathrm{O} 157$ infection (CON group). However, there were significant differ- 
Table 1. Total IgA in WGLF in different groups

\begin{tabular}{|c|c|c|c|c|}
\hline \multirow[b]{2}{*}{ Subject group } & \multirow[b]{2}{*}{$\mathrm{n}$} & \multicolumn{2}{|c|}{ Total $\operatorname{IgA}(\mu \mathrm{g} / \mathrm{ml})$ in WGLF } & \multirow{2}{*}{$\begin{array}{l}\mathrm{p} \text { value } \\
\text { (relative to } \\
\text { healthy } \\
\text { volunteers) }\end{array}$} \\
\hline & & Range & Mean & \\
\hline HV & 20 & $23.3-239.8$ & 63.6 & \\
\hline CON patients & 9 & $12.7-52.3$ & 40.3 & 0.06 \\
\hline GI patients* & 53 & $23.1-50.3$ & 50.3 & 0.3 \\
\hline $\mathrm{UC}$ patients & 24 & $32.8-239.5$ & 121.3 & 0.0008 \\
\hline CRO patients & 11 & $15.7-68.3$ & 36.5 & 0.03 \\
\hline
\end{tabular}

*See Materials and methods.

ences in the two groups of patients with inflammatory bowel disease (IBD: CRO and UC). The UC patients had significantly higher mean total IgA than HV group $(\mathrm{p}=0.0008)$ and CRO patients had lower mean total IgA than the other groups.

\section{Specific mucosal IgA antibody to OI57 LPS and} $R 3$ core in $W G L F$

Although the 'flow rate' of gut lavage fluid through the GI tract was similar for all groups investigated, specific IgA values were expressed as 'OD units $/ 100 \mu \mathrm{g}$ total IgA' in the WGLF. This allowed direct comparison where levels of total IgA varied. This had most influence on the levels measured from the two groups of IBD patients. The results are compared in Fig. 5. When the O157 LPS was the detecting antigen, the CON (8-113 weeks after infection) group had significantly higher levels of specific IgA (mean 3.17 OD units $/ 100 \mu \mathrm{g}$ total IgA) than the HV (mean 1.53 OD units $/ 100 \mu \mathrm{g}$ total IgA; $\mathrm{p}=0.008$ ) and GI (mean
1.77 OD units $/ 100 \mu \mathrm{g}$ total IgA; $\mathrm{p}=0.02$ ) groups (Fig. $5 a)$. When the response to the R3 core LPS was compared (Fig. 5b), CON (mean 1.87 OD units $/ 100 \mu \mathrm{g}$ total IgA) and GI (1.64 OD units/100 $\mu \mathrm{g}$ total IgA) groups also had higher levels of IgA to R3 core than the HV groups $(0.79$ OD units $/ 100 \mu \mathrm{g}$ total IgA; $\mathrm{p}=0.004$ and $\mathrm{p}<0.005$, respectively).

Specific IgA levels were compared between patients and HV groups by determining how much the levels varied in the groups of IBD patients who had extremes of total IgA levels, but with no evidence of prior exposure to $E$. coli $\mathrm{O} 157$. UC patients had significantly lower levels of IgA antibodies to O157 LPS than the HV group ( $\mathrm{p}<0.005$ ), whereas the CRO patients had higher levels than the HV group $(\mathrm{p}=0.02)$ and $\mathrm{UC}$ patients $(p<0.005)$ (Fig. 5a). These trends were similar but less pronounced for IgA antibodies to R3 core LPS (Fig. 5b).

\section{Correlation between systemic and mucosal humoral response}

There were no significant correlations between systemic IgG levels and mucosal IgA levels to either O157 or R3 core LPS (data not shown)

Inhibition ELISA to determine the specificity of $\operatorname{Ig} G$ antibodies in the 0157 LPS response

The purified O157 LPS used in the above assays contained both the O157 O-polysaccharide chain and the R3 core oligosaccharide moieties. An inhibition a

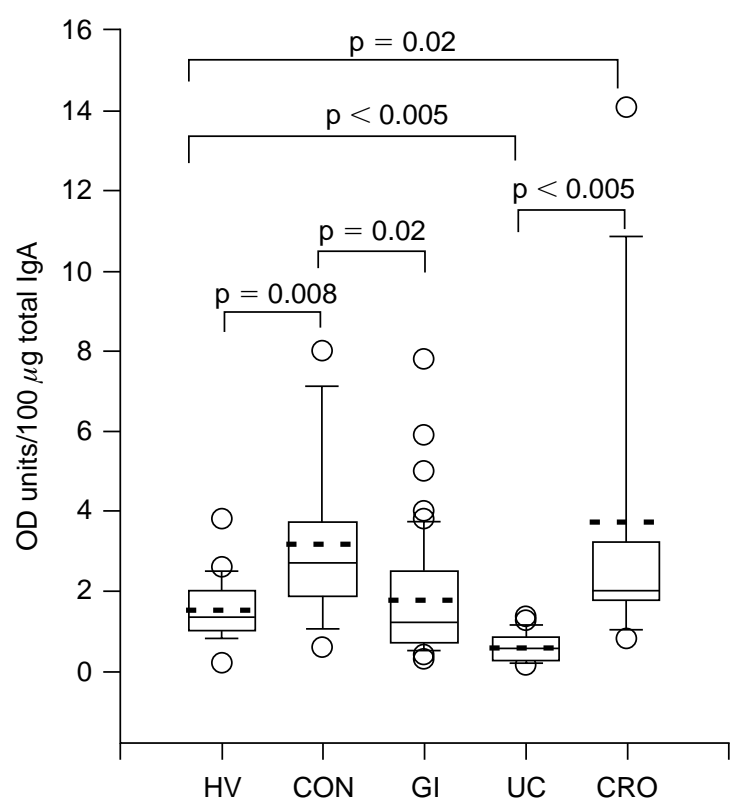

b

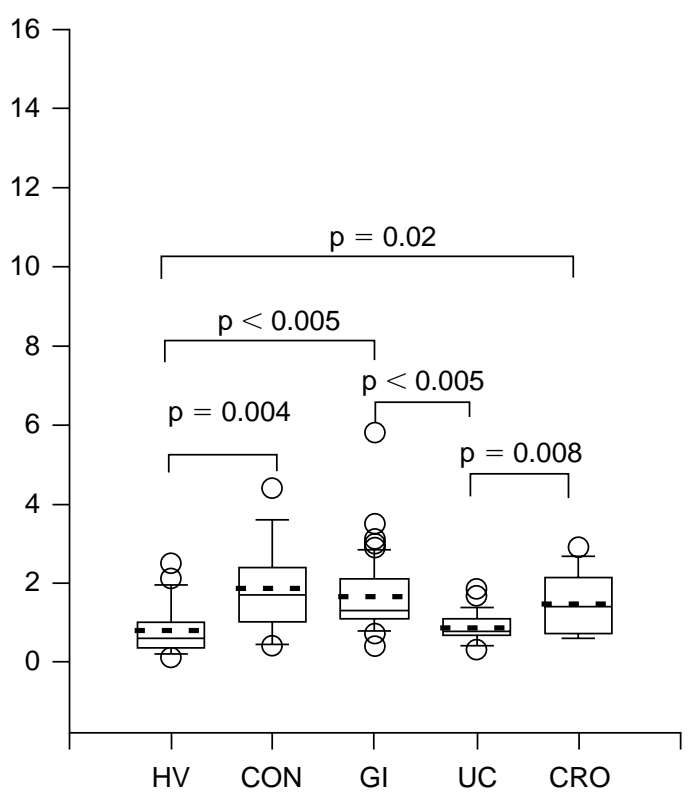

Fig. 5. IgA antibody responses to O157 LPS and R3 core LPS in WGLF by ELISA; units of IgA as OD $405 / 100 \mu \mathrm{g}$ total IgA. (a) IgA to O157 LPS; (b) IgA to R3 LPS. Healthy volunteers (HV); convalescent patients 8-113 weeks after infection (CON); GI 'immunologically normal' patients (GI); patients with ulcerative colitis (UC); patients with Crohn's disease (CRO). See legend to Fig. 2 for details of box plots 
assay was done to determine whether the specificity of the antibodies in this ' $\mathrm{O} 157$ ' response was to the $\mathrm{O} 157$ polysaccharide or to both the polysaccharide and the R3 core. The results summarised in Fig. 6 demonstrated that the R3 core LPS (inhibitor) inhibited the O157 response by 48.8 SEM $7.6 \%$ in healthy volunteers $(n=15)$ compared with only 28.4 SEM $7.4 \%(\mathrm{SEM})$ in convalescent patients $(\mathrm{n}=15)$. These findings indicate that a proportion of the response to O157 LPS was directed to the core oligosaccharide and that there was a significant difference $(p=0.06)$ in the response between $\mathrm{HV}$ and $\mathrm{CON}$ groups, the latter showing less of a response to the core oligosaccharide than to the O157 O-polysaccharide. Whole O157 LPS inhibited the O157 response by 90-95\% (data not shown).

Attempts to carry out similar inhibition experiments for IgA in WGLF were not successful.

\section{Measurement of IgA in saliva samples, and comparison with WGLF}

Because saliva is much easier to collect than WGLF, specific IgA levels in saliva were compared with those in WGLF. Specific IgA was detected in all saliva samples with values ranging from 0.5 to 7.9 OD units $/ 100 \mu \mathrm{g}$ total IgA for R3 and from 0.4 to $6.8 \mathrm{OD}$ units $/ 100 \mu \mathrm{g}$ total IgA for O157 LPS. There was no correlation between levels in saliva and WGLF for matched pairs and there were no statistical differences

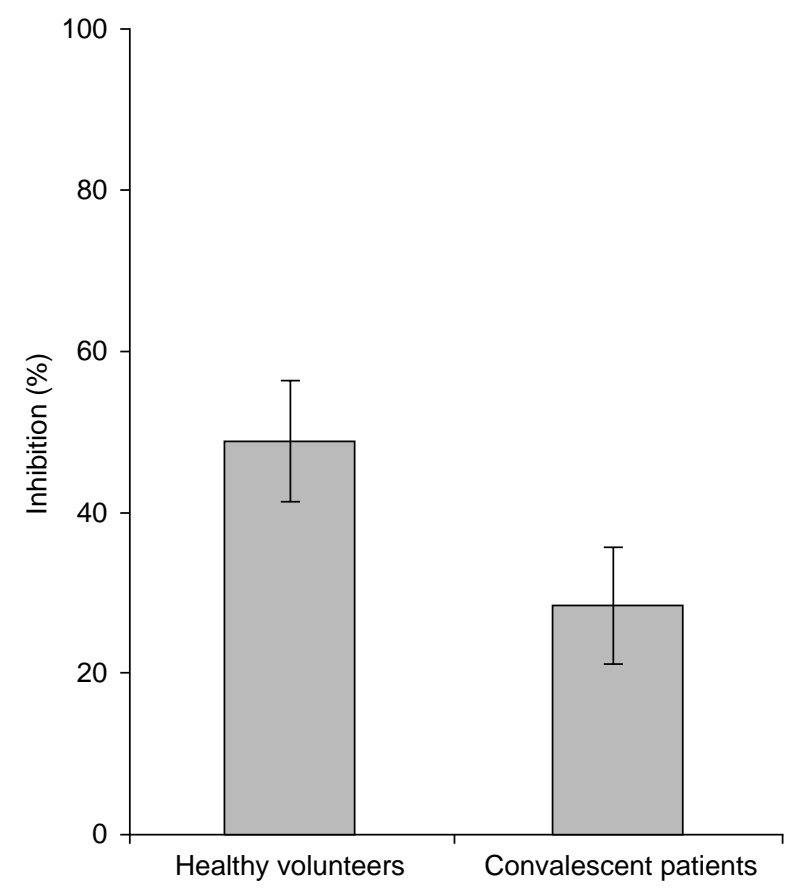

Fig. 6. Inhibition ELISA of $\mathrm{O} 157 \mathrm{IgG}$ antibody levels after pre-incubation of serum with R3 core LPS. Comparison between randomly chosen serum samples from 15 $\mathrm{HV}$ and $15 \mathrm{CON}$ patients. See text for details of inhibition assay. between the study groups. Repeat saliva samples taken 1-2 weeks apart showed great variation in specific $\operatorname{IgA}$ levels - varying by up to three-fold. There was no correlation when raw OD values were used.

\section{Discussion}

There have been numerous investigations of the systemic immune response to the Shiga toxins and cell antigens of E. coli $\mathrm{O} 157$ and other serotypes of EHEC [19-21]. LPS serology has been suggested as an aid to diagnosis of EHEC disease [22-24] and saliva has been advocated as a non-invasive and relevant source of mucosal antibody for detection of responses to O157 LPS [25]. However, as far as we are aware, this was the first study to investigate the mucosal immune response by use of the whole gut lavage technique.

The levels of serum antibody to the O157 LPS were generally as would have been predicted. In the acute phase of disease, IgM levels were high, then in the convalescent phase, IgG levels were raised. In health there was a variable level of $\operatorname{IgM}$ and $\mathrm{IgG}$ antibodies with a mean that is low compared with that of convalescent patients.

Whole O157 LPS, in addition to the O157 O-antigenic specific polysaccharide of varying chain length, also contains the R3 core oligosaccharide, both in the form where the terminal core sugar residue is free, in unsubstituted LPS, and also where the terminal residue is substituted by O-polysaccharide in smooth LPS. ELISA inhibition assays were performed to determine how much of the O157 LPS response was to the O157 polysaccharide and how much was to the R3 core, and it was found that in the HV group the total measured serum IgG response to O157 LPS was due to a combined response to both core oligosaccharide and Opolysaccharide; the R3 LPS inhibited c. 50\% of the reaction. In the $\mathrm{CON}$ group, the majority of the $\mathrm{IgG}$ antibody response was to the $\mathrm{O} 157$ polysaccharide, with only c. $25 \%$ being inhibited by R3.

In contrast, the measurement of antibodies with R3 LPS results only in detection of antibody to determinants in the core region of the LPS. Within core oligosaccharides there are epitopes shared between all other E. coli core types and the similar cores in the LPS of Salmonella and Shigella spp. [8], but we consider the terminal sugar residues in the unsubstituted form to be immunodominant. The response to the R3 core LPS generally paralleled the 0157 response, but with no marked increase during convalescence. In acute sera there was a marked increase in IgG antibody levels to the R3 core, suggesting a memory response of short duration.

In the healthy blood donor population, some indivi- 
duals had very high levels of IgG antibody to R3 core (3-8-fold greater than the mean). Results were similar when the $\mathrm{IgG}$ antibody levels to O157 LPS were measured (3-4-fold greater than the mean). If it was considered that this high level of antibody might be protective, the plasma from these hyperimmune individuals could be collected and used for passive immunisation, possibly directly into the GI tract (A. Ferguson, personal communication).

The observation by Ludwig et al. [26] that sera from about one-third of patients with HUS that gave positive results for $\mathrm{O} 157$ antibodies also reacted with LPS from E. coli O55, may have been due to reaction with the R3 core structure. Amor et al. [11] examined one O55 strain and found it to have an R3 core. However, it has also been hypothesised that an O55 EPEC strain was the ancestor of VTEC O157 [27]. The SH group was found to have elevated levels of IgM specific for the R3 core, which suggests that these individuals are being exposed to organisms with this core type at a higher frequency than the general population.

It has been reported by some workers that the main humoral response to LPS in VTEC infections is an IgM response [21], but in other studies IgM plus IgA [28], IgG alone [29], or either IgM or IgG [19] were more important. In our initial analysis, when convalescent patients were viewed as a whole, they did not have significantly higher levels of serum $\operatorname{IgM}$ or $\operatorname{IgG}$ antibodies to either antigen than the healthy volunteers (data not presented). This was because the majority of patients in the CON group were $>14$ weeks postinfection and their IgG and, most certainly, IgM antibody levels would have returned to normal. However, when the group was subdivided into a more recently infected subgroup (6-16 weeks), these had significantly higher IgG levels to the 0157 LPS. From these studies, the response to the R3 core oligosaccharide has been shown to complicate the measurement of the full magnitude of antibody levels, and the IgM and IgG responses vary. We suggest that in serological studies of antibodies (of whatever class) to E. coli O157 LPS, a differential or inhibition assay should be done to take account of the response to the specific O157 determinants and the common R3 core.

Although relatively low numbers of samples were obtained from convalescent patients, they indicate that they have significantly higher levels of mucosal $\operatorname{IgA}$, to both O157 LPS and R3 core, than healthy volunteers. This indicates that within the patient group (all of whom recovered from E. coli $\mathrm{O} 157$ infection without complications) mucosal antibodies to both antigens were produced and it is possible that they had a protective effect and prevented serious complications occurring. It would be interesting to know whether a high level of antibodies to the R3 core oligosaccharide, before infection with the pathogen, gives any protection.
The differences in IgA antibody levels between the two groups of IBD patients are intriguing. UC patients had the lowest levels of IgA to both antigens and the CRO patients had significantly higher levels. We can only speculate on the significance of this finding. UC patients may be generally more responsive to inflammatory insults by LPS because of an inherent inability to produce LPS-neutralising antibodies at the gut mucosa and UC is a disease of the surface layers of the colon. In contrast, Crohn's disease results in inflammation through the whole thickness of the GI wall and occurs at any point along the gut; it may allow bacteria and LPS to enter the systemic circulation to give a more generalised insult to the immune system [30]. When these two diseases have been monitored by the EndoCAb assay (manufactured by G.R. Barclay, Scottish National Blood Transfusion Service, Edinburgh), which measures antibodies reacting with the $\mathrm{R}$ cores of several different LPS types from different gram-negative bacteria, there has been a greatly increased level of serum IgG antibodies directed to R-LPS epitopes in patients with Crohn's disease [31].

In summary, this study has demonstrated that the response to whole E. coli O157 LPS can be difficult to interpret, as the measured response is to two different regions of the LPS molecule - the O157 polysaccharide and the R3 core oligosaccharide. The number of different epitopes represented in these structures is not yet understood. There are two main consequences of this observation. Firstly, when serology is used to monitor E. coli O157 infections, allowance must be made for the fact that some of the antibodies detected are to the R3 core. Secondly, the role, if any, of the response to the R3 core should be defined. This core is common to many of the E. coli and Shigella spp. that cause GI pathology [8], including the great majority of EHEC strains $[10,11]$. An increased level of $\operatorname{IgA}$ antibodies to this core type has been demonstrated in the WGLF from healthy volunteers from Bangladesh who are likely to be exposed regularly to E. coli and Shigella spp. that can cause diarrhoea [14]. We hypothesise that antibodies to this region of LPS may be protective, especially if the mucosal immune system of the GI tract is regularly exposed to this antigen, that it should be possible to induce a level of IgA antibody specific for the R3 LPS core by active immunisation (either natural exposure or vaccination) or passive immunisation, and this might be protective against strains of Enterobacteriaceae containing LPS with the R3 core.

This study was funded by the Chief Scientist Office, Health Department, Scottish Executive (Grant K/MRS/50/C2624). We are grateful to the nursing and laboratory staff of the GI Unit, Western General Hospital for help in collection and processing of specimens, to the many patients and volunteers who donated specimens, and to the Scottish National Blood Transfusion Service for the panel of normal sera. We thank Dr Sami Hoque for many useful discussions. 


\section{References}

1. Kaper JB, O'Brien AD (eds). Escherichia coli O157: H7 and other shiga toxin-producing E. coli strains. Washington, DC, American Society for Microbiology. 1998.

2. Ahmed S, Donaghy M. An outbreak of Escherichia coli O157:H7 in Central Scotland. In: Kaper JB, O’Brien AD (eds) Escherichia coli $\mathrm{O} 157$ : $\mathrm{H} 7$ and other shiga toxin-producing $E$. coli strains. Washington, DC, American Society for Microbiology. 1998: 59-65.

3. Sharp JCM, Coia JE, Curnow J, Reilly WJ. Escherichia coli O157 infections in Scotland. J Med Microbiol 1994; 40: 3-9.

4. Karmali MA. Human immune responses and immunity to shiga toxin (verocytotoxin)-producing Escherichia coli infection. In: Kaper JB, O'Brien AD (eds) Escherichia coli O157: H7 and other shiga toxin-producing E. coli strains. Washington, DC, American Society for Microbiology. 1998: 236-248.

5. Lingwood CA, Mylvaganam M, Arab $\mathrm{S}$ et al. Shiga toxin (Verotoxin) binding to its receptor glycolipid. In: Kaper JB, O'Brien AD (eds) Escherichia coli O157: H7 and other shiga toxin-producing E. coli strains. Washington, DC, American Society for Microbiology. 1998: 129-139.

6. Tesh VL. Cytokine response to shiga toxins. In: Kaper JB, O'Brien AD (eds) Escherichia coli O157: H7 and other shiga toxin-producing E. coli strains. Washington, DC, American Society for Microbiology. 1998: 226-235.

7. Louise CB, Obrig TG. Shiga toxin-associated hemolytic uremic syndrome: combined cytotoxic effects of shiga toxin and lipopolysaccharide (endotoxin) on human vascular endothelial cells in vitro. Infect Immun 1992; 60: 1536-1543.

8. Gibb AP, Barclay GR, Poxton IR, di Padova F. Frequencies of lipopolysaccharide core types among clinical isolates of Escherichia coli defined with monoclonal antibodies. J Infect Dis 1992; 166: 1051-1057.

9. Appelmelk BJ, An Y-Q, Hekker TAM, Thijs LG, MacLaren DM, de Graaf J. Frequencies of lipopolysaccharide core types in Escherichia coli strains from bacteraemic patients. Microbiology 1994; 140: 1119-1124.

10. Currie CG, Poxton IR. The lipopolysaccharide core type of Escherichia coli O157: $\mathrm{H} 7$ and other non-O157 verotoxinproducing E. coli. FEMS Immunol Med Microbiol 1999; 24: $57-62$.

11. Amor K, Heinrichs DE, Frirdich E, Ziebell K, Johnson RP, Whitfield C. Distribution of core oligosaccharide types in lipopolysaccharides from Escherichia coli. Infect Immun 2000; 68: $1116-1124$

12. Nelson D, Bathgate AJ, Poxton IR. Monoclonal antibodies as probes for detecting lipopolysaccharide expression on Escherichia coli from different growth conditions. J Gen Microbiol 1991; 137: 2741-2751.

13. Poxton IR, Myers CJ, Johnstone A, Drudy TA, Ferguson A. An ELISA to measure mucosal IgA specific for Bacteroides surface antigens in whole gut lavage fluid. Microb Ecol Health Dis 1995; 8: 129-136.

14. Hoque SS, Ghosh S, Poxton IR. Differences in intestinal humoral immunity between healthy volunteers from UK and Bangladesh. Eur J Gastro Hepatol 2000; 12: 1185-1194.

15. O'Mahony S, Barton JR, Crichton S, Ferguson A. Appraisal of gut lavage in the study of intestinal humoral immunity. Gut 1990; 31: $1341-1344$.
16. Ferguson A, Sallam J, O’Mahony S, Poxton IR. Clinical investigations of gut immune responses. Adv Drug Del Rev 1995; 18: $53-71$.

17. Hancock IC, Poxton IR. Bacterial cell surface techniques. Chichester, John Wiley \& Sons. 1988.

18. Scott BB, Barclay GR. Endotoxin-polymyxin complexes in an improved enzyme-linked immunosorbent assay for IgG antibodies in blood donor sera to gram-negative endotoxin core glycolipids. Vox Sang 1987; 52: 272-280.

19. Greatorex JS, Thorne GM. Humoral immune responses to shiga-like toxins and Escherichia coli O157 lipopolysaccharide in hemolytic-uremic syndrome patients and healthy subjects. $J$ Clin Microbiol 1994; 32: 1172-1178.

20. Kishore K, Rattan A, Bagga A, Srivastava RN, Nath NM, Shriniwas. Serum antibodies to verotoxin-producing Escherichia coli (VTEC) strains in patients with haemolytic uraemic syndrome. J Med Microbiol 1992; 37: 364-367.

21. Chart H, Scotland SM, Rowe B. Serum antibodies to Escherichia coli $\mathrm{O} 157: \mathrm{H7}$ in patients with hemolytic uremic syndrome. J Clin Microbiol 1989; 27: 285-290.

22. Chart H, Rowe B. Improved detection of infection by Escherichia coli $\mathrm{O} 157$ in patients with haemolytic uraemic syndrome by means of IgA antibodies to lipopolysaccharide. $J$ Infect 1992; 24: 257-261.

23. Chart H, Montgomery S, Rowe B. A rapid immunoblotting procedure for detecting serum antibodies to the lipopolysaccharide of Escherichia coli O157. Lett Appl Microbiol 1994; 18: $100-101$.

24. Cheasty $\mathrm{T}$, Robertson $\mathrm{R}$, Chart $\mathrm{H}$ et al. The use of serodiagnosis in the retrospective investigation of a nursery outbreak associated with Escherichia coli O157:H7. J Clin Pathol 1998; 51: 498-501.

25. Chart H, Jenkins C. Salivary antibodies to lipopolysaccharide antigens of Escherichia coli O157. Lancet 1998; 352: 371.

26. Ludwig K, Bitzan M, Zimmermann S, Kloth M, Ruder H, Müller-Wiefel DE. Immune response to non-O157 vero toxinproducing Escherichia coli in patients with hemolytic uremic syndrome. J Infect Dis 1996; 174: 1028-1039.

27. Whittam TS. Evolution of Escherichia coli O157: H7 and other shiga-toxin producing E. coli strains. In: Kaper JB, O'Brien AD (eds) Escherichia coli O157: H7 and other shiga toxin-producing E. coli strains. Washington, DC, American Society for Microbiology. 1998: 195-209.

28. Bitzan M, Ludwig K, Klempt M, König H, Büren J, MüllerWiefel DE. The role of Escherichia coli $\mathrm{O} 157$ infections in the classical (enteropathic) haemolytic uraemic syndrome: results of a Central European, multicentre study. Epidemiol Infect 1993; 110: 183-196.

29. Barrett TJ, Green JH, Griffin PM, Pavia AT, Ostroff SM, Wachsmuth IK. Enzyme-linked immunosorbent assay for detecting antibodies to Shiga-like toxin I, Shiga-like toxin II, and Escherichia coli O157: H7 lipopolysaccharide in human serum. Curr Microbiol 1991; 23: 189-195.

30. Gardiner KR, Erwin PJ, Anderson NH, Barr JG, Halliday MI, Rowlands BJ. Colonic bacteria and bacterial translocation in experimental colitis. Br J Surg 1993; 80: 512-516.

31. Gardiner KR, Barclay GR, McMillan SA, Halliday MI, Rowlands BJ. Differentiation of ulcerative colitis (UC) from Crohn's disease (CD). Gastroenterology 1992; 102: A626. 